THE INTERNATIONAL

REVIEW OF RESEARCH IN

OPEN AND DISTANCE LEARNING

\title{
Literacy at a Distance in Multilingual Contexts: Issues and Challenges ${ }^{1}$
}

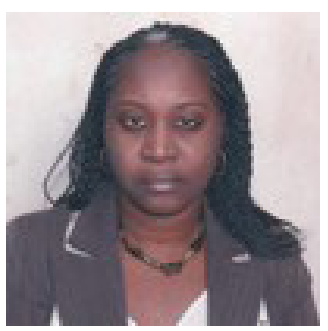

Christine I. Ofulue

National Open University of Nigeria

\section{Abstract}

Literacy is perhaps the most fundamental skill required for effective participation in education (formal and non-formal) for national development. At the same time, the choice of language for literacy is a complex issue in multilingual societies like Nigeria. This paper examines the issues involved, namely language policy, language and teacher development, and the role of distance education and information and communication technologies (ICTs), in making literacy accessible in as many languages as possible. Two distance learning literacy projects are presented as case studies and the lessons learned are discussed. The findings of this study suggest that although there is evidence of growing accessibility to ICTs like mobile phones, their use and success to increase access to literacy in the users' languages are yet to be attained or maximised. The implication of the lessons learned should be relevant to other multilingual nations that seek the goal of increasing access to learning and promoting development so as to harvest economic benefits.

Keywords: Literacy; multilingual societies; ICTs, case studies; development

\section{Introduction}

The role of literacy in the development of a nation cannot be overemphasised. As a basic human right and index for human development, literacy is at the core of UNESCO's Education for All (EFA) initiative. According to EFA's global monitoring report for 2006 (p.27), literacy skills are deemed essential in "today's knowledge societies, conferring benefits on individuals, communities and nations." The report also states that literacy was "one of the most neglected of the six goals adopted in 2000 by 164 countries at the World Education Forum in Dakar, Senegal." Global trends in literacy show that

- a majority of illiterate populations is found in developing countries;

- although the population of literate young people has improved significantly, 132 mil- 
lion youth worldwide are unable to communicate in a written language;

- there is a tendency for rural populations to have lower literacy levels than urban populations;

- illiteracy rates are highest in countries with the highest poverty rates; andabout half of the world's population lives in nine highly populated developing countries called the E-9 (E for education and 9 for nine countries), and they account for $40 \%$ of school dropouts and 70\% of the world's illiterate adults (EFA 2005); the E-9 countries include Bangladesh, Brazil, China, Egypt, India, Indonesia, Mexico, Pakistan, and Nigeria.

The presence of Nigeria among the E-9 underscores the challenge of literacy development amidst a large population and a large number of languages. Language is central to achieving literacy whether through formal or non-formal education. The ability to read and write in a language, whether it is exogenous or indigenous, constitutes an integral part of defining a literate individual. UNESCO (2003, cited in Robinson, 2007) reiterated its position on the role of mother tongues in education and the implementation of language policies:

UNESCO supports mother tongue instruction as a means of improving educational quality by building upon the knowledge and experience of the learners and teachers.

UNESCO supports bilingual and/or multilingual education at all levels of education as a means of promoting both social and gender equality and as a key element of linguistically diverse societies. (p. 60)

It is often the case in multilingual societies that many individuals do not have access to education because they are not literate in the choice of language of instruction. National language policies and the designation of languages for various purposes, including medium of instruction for formal and non-formal education, "can facilitate or hinder language development and literacy acquisition" (EFA 2005, 24). This study examines Nigeria's attempt to address the language issue through her language policy as a means of increasing accessibility to literacy. The lessons learned should be worthwhile for other multilingual nations. The role of language in the use of distance education and information and communication technologies (ICTs) to promote literacy is also examined through two case studies.

\section{The Role of Language in Literacy}

Although definitions of literacy have broadened over the years to include a wide range of skills, the basic skills of reading and writing remain at the core of any definition of literacy, while numeracy skills are viewed as supplementary. Also, these definitions do not specify language of literacy, thereby leaving the decision to individual countries. UNESCO's (EFA, 2005) long-standing definition of basic literacy does not specify the language of literacy: "A literate person is one who can, with understanding, both read and write a short simple 
statement on his or her everyday life" (p.153).

Neither is the language of literacy specified in UNESCO's definition of functional literacy:

A person is functionally literate who can engage in all those activities in which literacy is required for effective functioning of his (or her) group and community and also for enabling him (or her) to continue to use reading, writing and calculation for his (or her) own and the community's development. (p.30)

Indeed, there is evidence to support expanded definitions that take into account continuous acquisition of new skills such as those brought about by the technological age. There is some evidence that points to a growing number of educated but functional illiterates who are unable to perform certain daily tasks that characterise the current information technology age such as the ability to use the basic functions of a mobile phone (Ofulue, 2008). McCaffery et al. (2007) offer a layered view of literacy comprising skills, tasks, practices, and critical reflection, and emphasis could be on any layer depending on the purpose:

Literacy is rooted in the skills of reading and writing. These skills are used by individuals to accomplish tasks in their daily lives. These tasks are part of their literacy practices, socially and culturally rooted in the communities in which they live and work. Literacy can be a means for critical reflection on the world as a necessary part of becoming capable of creating change. (p.41)

There are also country-based definitions of literacy, which, in general, reflect its core concept, that is the ability to read and write, but with some variations. These various definitions, which have implications for how literacy is measured, vary in their language considerations, for example ability to write with understanding 1) in any language, 2) in a specified language, and 3) in at least one language. However, the critical question remains, in which language is attainment of literacy being measured and, by implication, in which language(s) is literacy learned or practiced? Based on research, which has shown that acquiring literacy in one's mother tongue enhances access to literacy in other languages, UNESCO (2003) has consistently encouraged the use of the mother tongue in education. The reality, however, is that many children around the world begin their schooling using a second language (Ouane 2003, EFA 2010). And many others are excluded by virtue of the non-availability of literacy opportunities in their mother tongues. With greater attention being paid to the role of language in literacy, the issue of in which language literacy should be learned becomes a very important consideration. The issue is even more critical for multilingual contexts like Nigeria. The linguistically diverse nature of Nigeria's language terrain has made this question a difficult and complex one to answer over the years and even more so in the current dispensation where additional variables, such as the negative effect of the minority/major language dichotomy on minority languages, are observed. 


\section{Nigeria's Demographic, Language, and Literacy Profile}

Nigeria is the most populous country in Africa and the ninth most populous country in the world with a linguistically diverse population of over ${ }^{1} 40$ million people, about 510 spoken languages, and a literacy rate of 66\% (UNICEF, 2009; Ethnologue, 2009). Population size is a key criterion for the classification of major versus minor languages. Approximately half of the population speak the three major languages, Hausa, Igbo, and Yoruba, as first or second languages. Regional languages are spoken by about one tenth of the population, namely Fulfulde, Nupe, Kanuri, Idoma, Tiv, Ibibio, Edo, Efik, and Ijaw, while the remaining languages are small group/minority languages. Many of these languages, especially the small group languages, have not been developed; they do not have orthographies and have not been assigned any significant role. Adegbija (2004) observed that only about 65 Nigerian languages have orthographies. English is Nigeria's official language and language of education; thus, it dominates the sociolinguistic space in terms of attitudes, power, and socioeconomic mobility. Going by Nigeria's literacy rate, about $66 \%$ of the population is literate in English, but there is no precise figure. The percentage given in this study is the percentage for the literate population in Nigeria as reported by UNICEF (2009), and it is based on school enrolment figures with English as the language of education. However, Adegbija (2003) was of the view that the population of English speakers is less than 20\%. Adegbija (1994) aptly surmises the linguistically diverse nature of Nigeria's population when he notes that "although precise statistics are not available, one can safely conclude from the evidence available that no language in Nigeria is spoken by as many as 50\% of the entire population as a first language" (p.16).

Based on Bamgbose's (1991) language topology, Nigeria shows the participation of at least five language types for literacy and communication and is illustrated in Table 1.

Table 1

Language Typology

\begin{tabular}{|l|l|l|l|}
\hline SN & Language type & Function & Languages involved \\
\hline $\mathbf{1}$ & Mother tongue & $\begin{array}{l}\text { Medium of informal education } \\
\text { in the home and among peers } \\
\text { within immediate community }\end{array}$ & All Nigerian languages \\
\hline $\mathbf{2}$ & $\begin{array}{l}\text { Language of immediate } \\
\text { community }\end{array}$ & $\begin{array}{l}\text { Lacal or regional lingua franca } \\
\text { munication }\end{array}$ & $\begin{array}{l}\text { All Nigerian languages, } \\
\text { minority languages in } \\
\text { particular }\end{array}$ \\
\hline & $\begin{array}{l}\text { Wider reach for education, and } \\
\text { communication as lingua franca, } \\
\text { national language. Also, of- } \\
\text { ficial language which is second } \\
\text { language for most and first lan- } \\
\text { guage for a growing number. }\end{array}$ & $\begin{array}{l}\text { Official (English) na- } \\
\text { tional (Hausa, Igbo and } \\
\text { Yoruba) and regional } \\
\text { (Fulfulde, Nupe, Kanuri, } \\
\text { Idoma, Tiv, Ibibio, Edo, } \\
\text { Efik, and Ijaw). }\end{array}$ \\
\hline
\end{tabular}




\begin{tabular}{|l|l|l|l|}
\hline 4 & Language of religion & $\begin{array}{l}\text { Language of religious communi- } \\
\text { cation }\end{array}$ & Arabic \\
\hline 5 & $\begin{array}{l}\text { Language of wider com- } \\
\text { munication }\end{array}$ & International communication & French \\
\hline
\end{tabular}

Source: Bamgbose (1991)

Research has shown that the most effective choice of language for basic literacy should be the language the child or adult is most familiar with (Adegbija, 2003). The language for conducting subsequent phases of literacy will depend on several factors, including the learner's profile (age, language needs, attitudes, and language skills already acquired) and the level/type of interaction with the immediate and wider society. These as well as other factors such as the historical experience, sociolinguistic features, and nationalistic views are considered in the choice of languages for education in Africa (Obanya, 2004, p.225). Nigeria's profile illustrates the complexities of language issues in multilingual nations as they seek ways to achieve mass literacy in learners' multiple languages.

\section{Language Policy and Literacy}

Language policies play a significant role in the spread of literacy. There is a strong link between language policies and the attitudes towards choice and development of indigenous languages. As noted in the EFA report (2005),

Language policies and practices have played, and continue to play, an important role in literacy and the development of literate communities. National language policies - the designation of an official language, the choice of language of instruction in schools and adult learning programmes can facilitate or hinder language development and literacy acquisition. Research consistently shows that learning to read and write in one's mother tongue enhances access to literacy in other languages. Yet literacy efforts in many countries lack a clear language policy. (p.24)

Nigeria's language policy is embedded within its education policy with the ultimate goal of promoting literacy in the English language while also achieving a degree of proficiency in a select number of Nigerian languages. The National Policy on Education (2004) states:

Government appreciates the importance of language as a means of promoting social interaction and natural cohesion; and preserving cultures. Thus every child shall learn the language of the immediate environment. Furthermore, in the interest of national unity it is expedient that every child shall be required to learn one of the three Nigerian languages: Hausa, Igbo and Yoruba. For smooth interaction with our 
neighbours, it is desirable for every Nigerian to speak French. Accordingly, French shall be the second official language in Nigeria and it shall be compulsory in primary and Junior Secondary Schools but a NonVocational Elective at the Senior Secondary School... The medium of instruction in the primary school shall be the language of the environment for the first three years. During this period, English shall be taught as a subject. From the fourth year, English shall progressively be used as a medium of instruction and the language of the immediate environment and French shall be taught as subjects. (pp.5, 10-11)

In principle, Nigeria's language policy on education prescribes a role for all Nigerian languages that are languages of the immediate environment as languages of instruction for pre-primary and the first three of six years of primary education. English is prescribed as a medium of instruction from the fourth year of primary education onwards, and as a subject. A minimum of one national language is prescribed for learning as a subject at the secondary education level. French is a recent feature in the policy as a second official language and is prescribed for learning as a subject. In other words, the learner should be literate in a minimum of three to four languages at the end of 12 years of formal schooling. The policy is silent on the language of instruction for mass literacy, adult, and non-formal education. The assumption is that the language of instruction would be in the language of the immediate environment.

Language policies affect attitudes because prescription of which language should be used for what is a key factor that affects the attitudes of groups towards their mother tongues (Ouane, 2003). In countries like Nigeria where the policy assigns important roles to the exogenous language, that is English, it is only natural that attitudes towards learning using the mother tongue will suffer. By virtue of its accorded status, there is a greater motivation toward acquiring English via formal education than toward acquiring Nigerian languages. Although the policy prescribes a function for Nigerian languages, the cost of promoting learning in multiple languages is often cited as a major challenge to its implementation. The result is a migration to languages of instruction within the immediate environment for which materials are available. Urban/rural population statistics for Nigeria show that a greater percentage (52\%) of the population lives in rural areas where the mother tongue is usually the first and sometimes only language spoken by pre-primary school learners. The language policy, as practiced, excludes a fair percentage of these learners from literacy because the language of instruction is not their mother tongue. In the urban setting, it is doubtful that the policy is being implemented as most schools use English as the preferred medium of instruction. Language policies should be designed to promote literacy in the mother tongues by assigning to them functionally significant roles that are equally as important as those assigned to the languages of power, which are used to attract positive economic and social benefits to the speakers and thus have a positive impact on learners' at- 
titudes towards their mother tongue. Based on the Indian experience, Rao (2007) observes that a clearly articulated framework for achieving literacy is a major factor in ensuring effective implementation of sound policies. Such a framework should adopt a multilingual approach for the training of teachers to teach in multiple languages and for the development of both teaching and supplementary reading materials in multiple languages.

\section{Teacher Development}

The EFA (2005) report notes the vital importance of teachers to the success of literacy programmes, yet the lack of adequate and regular remuneration, job security, training opportunities, and continuous professional support have undermined their importance. The report also states that "unless the professional development of literacy educators and their trainers is taken seriously, progress towards more literate societies will be severely constrained" (p. 35). Teaching within multilingual contexts is often beset by problems of language materials, curriculum, time allocation, and availability of teachers (Bamgbose, 1991; Obanya, 2004). Instructional delivery is still very much dependent on traditional text methods in the absence of other forms of resources. Traditional methods require large numbers of teachers, infrastructure, and language materials. Although these issues are not unique to language teaching, coping with multiple languages that require a multiple number of teachers and materials becomes an issue. As is the case with highly populated countries burdened with high budget requirements for formal and informal education, the implementation of a language policy involving multiple languages for literacy becomes an additional burden. Although teacher development has improved over time, the EFA progress report notes that in many developing countries including Nigeria, there is still a shortfall in the number of trained teachers. To address the problem, a focus on teacher development was adopted as one of the resolutions at the $7^{\text {th }}$ Ministers' Review Conference of E-9 countries. However, the training of teachers in the language(s) for literacy should perhaps be given more emphasis than it currently receives because the acquisition of language skills is the basis for literacy and subsequent skills for development.

\section{Multilingualism and Language Development}

In addressing issues of multilingualism in adult literacy, Robinson (2007) states:

Literacy is about communication and is therefore fundamentally a language-based activity; there can be no discussion of literacy without asking in which language literacy will be acquired and practised and this implies a clear knowledge of what languages specific groups of people use for communication in their daily lives. (p.59)

There is a strong link between language and literacy especially in multilingual contexts where the language for formal education is often prescribed, while that of informal education is usually negotiated depending on the language of the immediate or wider community and on the availability of teaching resources in that language. The number of languages recommended by the policy implies that a learner will be exposed to at least four languages 
apart from the mother tongue over a period of 12 years of schooling. Indeed, linguistic diversity appears to be a crucial factor in accessing learning in correlation with high population, poverty, and literacy rates. According to the EFA (2006) report on literacy,

A majority of countries facing salient literacy challenges are linguistically diverse. Decisions on language must balance political and ethnic sensitivity, pedagogical effectiveness, costs and learner preferences. The extra cost of training teachers and developing materials in multiple languages must be weighed against the inefficiency of teaching in languages that learners do not understand. A multilingual policy should also ensure that learners have opportunities to gain literacy skills in a second/official language that may be of wider use. (p.25)

Table 2 presents comparative information on the linguistic diversity that exists in the E-9 countries and literacy rates, population, and poverty.

Table 2

\section{E-9 Countries' Statistics}

\begin{tabular}{|c|c|c|c|c|c|c|}
\hline & \multirow[t]{2}{*}{ Country } & \multirow[t]{2}{*}{ Population } & \multicolumn{2}{|c|}{ Languages } & \multirow{2}{*}{$\begin{array}{c}\text { Literacy rates } \\
\text { (adult and } \\
\text { youth) \% }\end{array}$} & \multirow{2}{*}{$\begin{array}{c}\text { Population } \\
\text { living below } \\
\text { USD1.25/per } \\
\text { day }\end{array}$} \\
\hline & & & 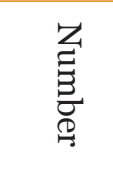 & 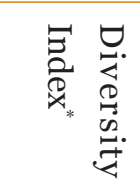 & & \\
\hline 1. & China & $1,345,751,000$ & 296 & 0.509 & 96.5 & 16 \\
\hline 2. & India & 1,198,003,000 & 445 & 0.940 & 75 & 42 \\
\hline 3. & Indonesia & $229,965,000$ & 722 & 0.816 & 95 & 29 \\
\hline 4. & Brazil & $193,734,500$ & 193 & 0.103 & 95 & 5 \\
\hline 5. & Pakistan & $180,808,000$ & 77 & 0.762 & 64 & 23 \\
\hline 6. & Bangladesh & $162,221,000$ & 46 & 0.387 & 68 & 50 \\
\hline 7. & Nigeria & $154,729,000$ & 521 & 0.869 & 66 & 64 \\
\hline 8. & Mexico & $109,610,000$ & 297 & 0.137 & $95 \cdot 5$ & 4 \\
\hline 9. & Egypt & $82,999,000$ & 27 & 0.536 & 79 & 2 \\
\hline
\end{tabular}

Sources: UNICEF (2009); Ethnologue (2009). *The Index column reports Greenberg's diversity index. This is the probability that any two people of the country selected at random would have different mother tongues (Lieberson, 1981). The highest possible value, 1 , indicates total diversity (that is, no two people have the same mother tongue) while the lowest possible value, o, indicates no diversity at all (that is, everyone has the same mother tongue). The computation of the diversity index is based on the population of each language as a proportion of the total population (Ethnologue, 2009). 
In Table 2, at least six of the E-9 countries have at least 190 languages or more. Figures for Nigeria and India show the highest correlation through high number of languages, low literacy rates, and high poverty rates. Although literacy rates have improved generally among the E-9 countries, Nigeria has the highest percentage of population living below the international poverty line at $64 \%$ and the second lowest for literacy rate at $66 \%$. With about half of the Nigerian population under the age of 18 years, these figures have significant implications for both human and economic resources. Multilingualism is a key factor in countries like Nigeria because it constitutes an additional socioeconomic burden, which in turn has a negative impact on literacy efforts as a result of learners who are denied access by virtue of the non-availability of literacy materials in their languages. As noted previously, the economic challenge of training teachers and developing materials in multiple languages must be weighed against the inefficiency of teaching in languages that learners do not understand (EFA, 2006). The benefits of using multiple languages include the removal of the language barrier and expansion of access to literacy. Thus, learners are able to access literacy in their mother tongues without having to first learn another language based on the premise that literacy is most effectively acquired first in the mother tongue or in learners' first language. Note also that literacy in the mother tongue facilitates the acquisition of literacy in other languages.

\section{Promoting Literacy Using Distance Education and ICTs}

There is general consensus that distance learning and ICTs can provide opportunities for formal and non-formal literacy learning by adults, though access to technology is highly uneven in many places. It has also been noted that ICTs and distance learning have more immediate potential for offering professional development to literacy educators rather than for running literacy programmes (EFA, 2006, p.25). Unfortunately, ICTs rely on international languages and are therefore often not readily accessible to learners as is the case in countries like Nigeria (Pennells, 2005). Access to literacy in multiple languages is perhaps the greatest challenge for multilingual societies. In addressing the issue of access, the E-9 countries recognised ICTs and distance education as important tools to improve teacher development. By extension, access to literacy should also be positively affected because teacher development is a key factor in promoting literacy. The need for distance education to be mediated by ICTs is borne by the factors of limited access to resource materials in multiple languages for learning, the cost of developing them, lack of trained teachers to facilitate the learning process with attendant costs, and lack of opportunities for learners (exposure to information and use) to develop their language skills. Because language learning is a skill-based venture, it requires ample opportunity (exposure and use) to ensure the development of the skills. Distance education and ICTs make it possible to take learners' characteristics into consideration in the selection of the language for instructional delivery and thereby ensure that learning is conducted in the learners' first language at minimal costs.

A National Information Technology (IT) policy was approved for Nigeria in 2001. The National Information Technology Development Agency (NITDA) and the Nigerian National 
ICT for Development (ICT4D) Strategic Action Plan Committee were established to drive the implementation of the policy. Encouraging the use of ICTs in education is one of the objectives of the policy. Such a policy should serve as a catalyst to making mass access to learning possible through the use of appropriate technologies. While there have been experiments with the use of print, radio, and television in mass literacy projects, the possibilities of using newer ICTs are yet to be fully maximized for learning. The phenomenal growth in the use of mobile phones in Nigeria is an example of new ICTs with potential benefits for literacy efforts. From less than 1 million fixed and mobile lines in 2000, when the new telecommunications policy was enacted, to over 92 million subscribers 10 years later and with a projected growth rate of $25 \%$ per annum, mobile telephony has the potential not only to close the developmental gap, but also to provide access to learning for development in Nigeria. Teledensity was at $0.33 \%$ in 2001 and rose to $56.32 \%$ by 2010 (NCC, 2010; Pyramid Research, 2010). There has also been appreciable growth in the spread and rural penetration of mobile telephony with $83 \%$ coverage of the population (World Bank, 2008). Mobile telephony has overtaken use of the Internet, which stands at $16 \%$ of the population, and television users, at $25 \%$ of the population (World Bank, 2008; Internet World Statistics, 2010). This wide margin is not unrelated to the fact that it costs fives times more to access the Internet than to access the mobile phone.

Pennells (2006) is of the view that despite the significant growth of the telecommunications industry in Africa and of mobile telephones as the "telecommunication medium of choice," including their use in distance learning to send short text messages to learners and for communication between learners and their instructors, mobile phones are not likely to have a major impact on mass education due to affordability by many non-literate people and literacy programmes (p.34). However, research shows that literacy not affordability is the major obstacle to the mobile phone being used to support mass education. In a comprehensive study on mobile telephony in Nigeria, Tiemo (2006) reports that this ICT tool has proven to be very successful and sustainable among the rural Nigerian population. However, low levels of education and illiteracy reinforced by poverty are among the factors limiting access to ICT infrastructure in developing countries and especially among women (2006, p. 24). In a study conducted among rural women mobile phone users, it was discovered that language constituted a major barrier in their ability to operate their phones even though they were literate in their indigenous languages (Tiemo, 2006, p. 87). The study recommended that indigenous languages should be taken into consideration in the production of mobile phones, and education programmes for users should be conducted. Because $52 \%$ of Nigeria's population is rural and literacy figures are lower among this group, there is significant justification for this recommendation. With various recorded successes of rural mobile telephony, this ICT tool has the potential to be used for promoting literacy. However, the indigenous languages will need to be given more prominent roles because they are often the first and perhaps only language of the learners. Elsewhere, in Bangladesh for example, mobile technologies with literacy-learning facilities for various non-literate groups are being utilised with subsequent improvement in "literacy rates as well as in health, girls" school enrolment, and use and conservation of water systems" (COL 2005; Rezwan, 2004, cited in Pennells, 2006, p. 21). It is possible that the benefits accrued by mobile technologies in 
Bangladesh could materialize in Nigeria.

\section{Case Studies of Literacy Projects at a Distance}

Although print has remained the main medium for literacy because of its relative affordability and accessibility compared with electronic media, ICTs offer better possibilities for creating access to learning. Pennells (2006, pp. 21,34) notes that radio has "continuing potential for use in literacy development," particularly among learner groups who are separated by distance. He reports that the use of distance learning as a support to literacy development has been very significant in the area of teacher training, particularly in Africa using a blended approach of face-to-face and ICT-mediated instruction. Aderinoye et al. (2007) corroborate the relevance of the radio in promoting literacy in the indigenous languages in Nigeria. Two examples of literacy programmes mediated by technologies are presented below.

\section{Literacy-by-Radio Programme}

A National Commission for Mass Literacy, Adult and Non-Formal Education was established in 1990 as part of Nigeria's response and commitment to attaining the EFA goals. It is instructive to note that the major problems in implementation as identified by the Commission are the same as those affecting the delivery of formal education. They include funding, infrastructure, teaching personnel, and community ownership (Khalid, $2004 \mathrm{p}$. 28). These problems are also the reason the Commission suffered a setback in carrying out its mandate. However, the government has renewed its commitment to EFA and has agreed to achieve the EFA goals by 2015 .

The Literacy-by-Radio project is one example of an implementation step toward the attainment of EFA by 2015. The project was inaugurated in 2004 by the Federal Government of Nigeria in collaboration with UNESCO through the National Commission for Mass Literacy, Adult and Non-formal Education (NMEC) with technical input from Cuba.

During the pilot stage of the project, 12 states were used, two each from the six geopolitical zones of the country. At the state level, local governments were selected to participate in the project. For example, reports from Niger state show that two local governments, Agaie and Lapai, each with five communities were selected to participate in the project. As part of their contribution and as a means of owning the project, the local governments provided 10 facilitators, translation and production of primers, and monitoring facilities. Facilitators went through two weeks of training. A total of 213 females and 6 males in the two local government areas participated in the programme. Based on the Cuban model, a blended approach combining listening to radio broadcasts of the lessons with specially designed primers that use pictures and signs to guide the learner in acquiring literacy and numeracy skills in the language of the immediate environment and periodic face-to-face interactive sessions with facilitators was adopted. The instructional materials were scripted for radio broadcasts in Nupe, the language of the immediate environment. The radio broadcasts were used to supplement the face-to-face interactive sessions with the learners. Learners 
met at a specific time and location to listen to the broadcast. Assessment of learning was conducted at the end of the period. According to the report, the success rates of the Literacy-by-Radio programme were better than that of the conventional method. For example, the dropout rate was lower in comparison; it was more effective for adult learners; and learners developed literacy skills within a shorter period (Niger State Agency for Mass Education, 2008). The results of the evaluation commissioned by UNESCO also showed "that learner enrolment projections were exceeded in many instances (often by as much as 50\%) and that the project can be adjudged a success in every sense" (UNESCO, 2007). Having recorded a significant level of success, the government is supporting the scaling up of the programme to cover the entire country. The 36 states and the Federal capital territory are reported to have produced lessons in various local languages for broadcasting. Learners are expected to acquire basic literacy skills in their indigenous languages within three to four months (Khalid, 2009)

The successful outcomes recorded for the pilot project were aided by local community ownership and the significantly higher participation of women than men during the pilot stage of the programme. In Niger State, the lack of continuous funding and increased participation were identified as major threats to long-term sustenance of the project. A holistic evaluation of the project showed that if any meaningful mass literacy is to be achieved in Nigeria, the use of radio is appropriate to address problems of "multilingual context, culture, distance from one community to another, and ethnicity" (UNESCO, 2007).

Recently, the Commission received a boost when additional funds were released for the continual airing of the Literacy-by-Radio programme and the supply of 100 radio sets to each of the 774 local government areas in the country and the training of 1,800 facilitators (Daily Champion, 2010). The project is an example of basic, low-end literacy programming in which the use of learners' indigenous languages undoubtedly contributed to its recorded success.

\section{Virtual Teacher Training Programme}

The Virtual Institute for Higher Education Programme (VIHEAP) and the Virtual Institute for Higher Education in Africa (VIHEAF) were launched in 2003-2004 as collaborative initiatives between the National Universities Commission (NUC) and the UNESCO Harare Cluster office. The institutes were established for the purpose of developing capacity at the individual and institutional levels in the Africa region through the provision of online programmes. The target audience included higher education teachers.

The aim is to provide programmes that support the development of pedagogical skills as part of NUC and UNESCO's contributions to improving the quality of teaching and learning in schools across sub-Sahara African countries. The objectives include the following: provision of Internet-based training on modern methods of teaching and learning in higher education; the upgrade of knowledge and skills on topics such as teaching large classes, effective utilisation of (meagre) resources, modern methods of assessment and evaluation of students' performance, basic guidance and counselling techniques, basic skills of curriculum development, and techniques for writing winning grant proposals; information on 
best practices in university teaching and how to deal with academic and social vices such as examination malpractice, plagiarism, and cultism; and current information and skills in HIV/AIDS education.

The first year of the programme constituted a pilot study on conducting training at a distance via the Internet. Over 400 teachers registered to participate in the programme. The language of instruction was English. The content was assembled into modules. Each module was made up of lessons divided into sub-topics. Each module contained an introduction and a set of objectives. The lessons included an introduction, objectives, structured content, summary, and references to consult for further reading. Figure 1 presents a graphic illustration of a lesson.

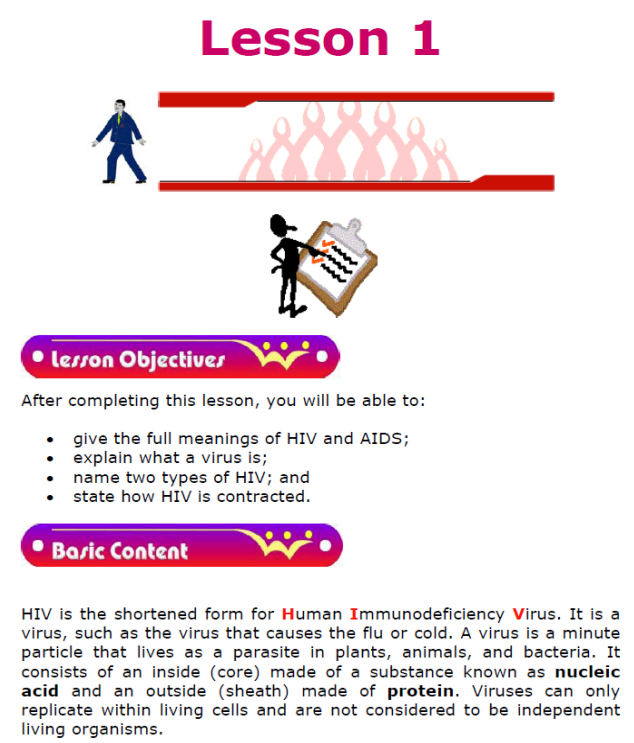

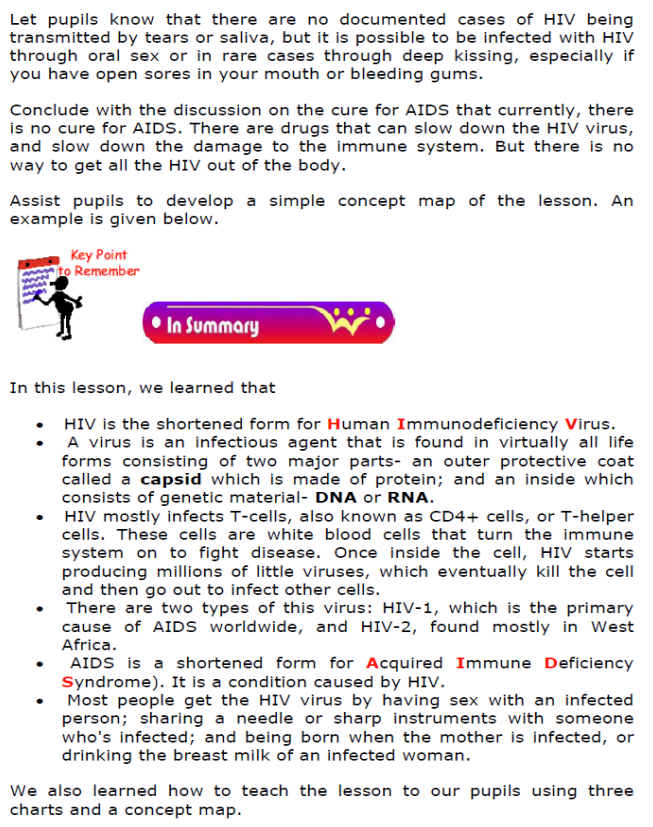

Figure 1. VIHEAF online lesson (source: www.ibe.unesco.org).

Students are required to participate in online discussions, quizzes, and a test or project at the end of the module. The programme, which assumes computer literacy skills as a prerequisite for participation and literacy in the English language, is an example of a further high-end literacy programme. It is worthy of note that the online programmes that had been discontinued after their first year were resuscitated and merged in 2008 under the auspices of UNESCO and Bamako cluster office as a programme in collaboration with the NUC and partners, including the Association of African Universities (AAU) and Association for the Development of Education in Africa (ADEA). The online delivery system has also been updated with additional new courses in response to demand (UNESCO, 2009).

\section{Lessons Learned from the Case Studies}

The main lessons learned from the two case studies described are summarised as follows. 
- The comparatively significant success rates reported for the pilot phase of the Literacyby-Radio programme confirm that radio remains a basic, relevant, useful, and effective tool with the potential of reaching more people, who are separated by distance, in the language of their choice.

- Ownership of the project through collaboration with local stakeholders is a key factor to the success of these projects.

- It is important that plans and logistics for the sustainability and long-term maintenance of literacy programmes are a part of the initial project framework because the lack of a long-term plan constitutes a major threat to positive cumulative outcomes of these literacy projects.

- Newer technologies like computers, Internet, and electronic training materials are very useful for continuing professional development purposes, such as the training of facilitators and teachers.

- Contrary to some views cited earlier, there is great potential for the use of modern ICTs such as mobile phones for mass access to learning at a distance in multiple languages.

Distance learning using ICTs can extend the reach of literacy programmes to learners in multiple languages. However, the success of such programmes is dependent on proper consideration of learners' needs and the language of instruction. The success recorded in the Indian experience, such that literacy rates improved by $65 \%$, is attributed in part to the careful selection of the language used and the careful preparation of teaching-learning materials so that content was relevant to the learners and contained illustrations, exercises, and self-evaluation at the end of each unit (Rao, 2007). Adapting to new technologies like mobile phones is not likely to pose challenges to young learners in the $21^{\text {st }}$ century, who have been observed to take to the use of technologies faster and more easily than adults (Kanwar, 2008). Adult learners on their part have been noted to tend to prefer to learn in regional or national language(s) because of the immediate socioeconomic benefits to them (EFA 2005, p.204). For both groups, access to literacy mediated by ICTs is beneficial. Reporting on a case study of illiterate rural adult mobile phone users in Nigeria, Tiemo (2006) showed that the socioeconomic benefits they derive make mobile phones a successful and sustainable tool for mass access. However, they are not able to maximise the use of their phones due to literacy/language barriers.

\section{Conclusion}

The aim of this paper was to examine the issues associated with promoting literacy for development amidst a linguistically diverse society like Nigeria and the contributions of distance learning using ICTs to achieve this goal. As one of the key factors for sustainable development and for achieving the EFA goals and Millennium Development Goals (MDGs), it is necessary to develop cost-effective and sustainable ways of creating mass access to literacy. Based on the premise that learning is best conducted in the learners' first language, 
literacy should be provided in a language that is most accessible to learners and that is most relevant for their needs. But because there are multiple first languages, with financial constraints affecting language development and teacher development, access to literacy programmes in the learners' first language remains a problem in Nigeria and consequently a barrier to development.

The findings of this study suggest that although there is evidence of growing access to ICTs like mobile phones, their use and success to increase access to literacy in users' languages, similar to the economic benefits that have been achieved, are yet to be attained and maximised. Opportunities for literacy should be encouraged using as many languages as possible, and distance learning makes it possible to turn the complexities of linguistic diversity into gains through the use of appropriate technologies that are accessible and that meet the needs of the learners. In view of this positive trend in Nigeria and given the linguistically heterogenous context and the diversity of literacy needs, the adoption and adaptation of new technologies to learning among both young and adult learners needs to be explored further. 


\section{References}

Adegbija, E. E. (2004). Multilingualism: A Nigerian case study. Trenton, New Jersey: Africa World Press.

Adegbija, E. E. (2003). Central language issues in literacy and basic education: Three mother tongue education experiments in Nigeria. In Adama Ouane (Ed.), Towards a multilingual culture of education (pp. 299-332). Hamburg: UNESCO Institute for Education.

Aderinoye R.A., Ojokheta K.O., \& Olojede A.A. (2007). Integrating mobile learning into nomadic education programmes in Nigeria: Issues and perspectives. The International Review of Research in Open and Distance Learning, 8(2).

Bamgbose, A. (1991). Language and the nation: The language question in sub-Saharan Africa. Edinburgh: Edinburgh University Press.

Charles-Iyoha, C. (2006). Mobile telephony: Leveraging strengths and opportunities for socioeconomic transformation in Nigeria. Lagos: Centre for Policy and Development.

Daily Champion (2010). Nigeria: Mass literacy gets N96.5 million boost, Retrieved from www.allAfrica.com.

Federal Republic of Nigeria (2004). National policy on education ( $4^{\text {th }}$ ed.). Lagos: Federal Government Press.

Internet World Statistics (2010). Nigeria. Retrieved from http://www.internetworldstats. com/af/ng.htm

Kanwar, A. (2008, March 26). Digital divide or digital dividend? A developing world perspective. Paper presented at the National Open University of Nigeria.

Khalid, A. (2004, June 14). Adult and non-formal education delivery in Nigeria. Paper presented at the Regional Conference on Adult Education and Poverty Reduction in Garborone, Botswana.

Lewis, M. Paul (ed.), (2009). Ethnologue: Languages of the world (16 ${ }^{\text {th }}$ ed.). Dallas, Texas.: SIL International. Retrieved from http://www.ethnologue.com/.

McCaffery J., Merrifield, J., \& Millican, J. (2007). Developing adult literacy. United Kingdom: Oxfam GB.

Nigerian Communications Commission (NCC), (2010). Industry statistics. Retrieved from http://www.ncc.gov.ng/

Niger State Agency for Mass Education (2008). Status report of the FGN/UNESCO literacy 
through radio project. Niger State Government, Nigeria.

Obanya, P. (2004). The dilemma of education in Africa. Ibadan: Heinemann Educational Books.

Ofulue, Christine I. (2008) Educational versus functional literacy: A study of attitudes of mobile phone users to the acquisition of basic ICT skills. In English and the Challenges of Literacy in the $21^{\text {st }}$ Century. Proceedings of the $22^{\text {nd }}$ Annual Conference of the Nigerian English Studies Association (NESA) (pp. 64-73). Ile-Ife: Nigerian English Studies Association.

Pennells, J. (2005). Literacy, distance learning and ICT (Background paper for EFA Global Monitoring Report). Paris: UNESCO.

Rao, S.I.V. (2007). Indian experience of mass literacy campaigns: Lessons and challenges. In Report of the International Workshop on Mass Literacy Campaign as a strategy for achieving the EFA and MDGs on education in Nigeria (pp. 39-58). Abuja: UNESCO.

Robinson, C. (2007). Issues of multilingualism in adult literacy. In Report of the International Workshop on Mass Literacy Campaign as a strategy for achieving the EFA and MDGs on education in Nigeria (pp. 59-73). Abuja: UNESCO.

Tiemo, P. A. (2006). An assessment of the literacy level of global system of mobile communication among rural women in the Niger Delta Region of Nigeria. In C. CharlesIyoha (Ed.), Mobile telephony: Leveraging strengths and opportunities for socioeconomic transformation in Nigeria (pp.80-89). Lagos: Centre for Policy and Development.

UNESCO Institute of Education (2003). Towards a multilingual culture of education. Hamburg: UNESCO Institute for Education.

UNESCO (2006). EFA global monitoring report 2006: Literacy for life. Paris: UNESCO Publishing.

UNESCO (2010). EFA global monitoring report 2010: Reaching the marginalised. Paris and London: UNESCO Publishing and Oxford University Press

UNESCO (2007). Report of the International Workshop on Mass Literacy Campaign as a strategy for achieving the EFA and MDGs on education in Nigeria. Abuja: UNESCO.

UNICEF (2009). At a glance: Statistics. Retrieved from http://www.unicef.org/infobycountry/statistics.html 
UNESCO Bamako Cluster Office. Virtual Institute of Higher Education in Africa. Retrieved from http://www.unesco-bamako.org/viheaf

UNESCO Harare Cluster Office. Virtual Institute of Higher Education in Africa. Retrieved from www.ibe.unesco.org/fileadmin/user_upload/HIV_AIDS_375_EN.pdf

World Bank (2008). ICT at a glance - Nigeria. Retrieved from http://devdata.worldbank. org/ict/nga ict.pdf

\section{Notes}

${ }^{1}$ This is a revised version of a paper that was first presented at the $5^{\text {th }}$ Biennial Pan African Commonwealth Forum (PCF5), held at the University College of London, United Kingdom $13-17$ July 2008.

\section{Athabasca University $\mathbf{I}$}

(c) 